\title{
IMPLEMENTASI WEB ELEKTRONIK (E-COMMERCE) DI TOKO PECAH BELAH CENTER DALAM MENINGKATKAN PERSAINGAN BISNIS PERDAGANGAN
}

\author{
Marini, Sarwindah \\ Program Studi Sistem Informasi, STMIK ATMA LUHUR \\ J1. Jend. Sudirman, Selindung Lama \\ arinimarin44eatmaluhur.ac.id, indah_syifadatmaluhur.ac.id
}

\begin{abstract}
Implementation of Electronic Web (E-Commerce) that can make transactions for the community and increase trade. Electronic Web Implementation (E-Commerce) uses the OOAD method (Object Oriented Analysis Design). The development phase of design modeling uses problem analysis, and application marketing needs, process model design, data model design, application program creation, application implementation. This research serves to find out that internet usage in the present time has experienced significant development and benefits in the business field. This is mainly felt by large scale companies. The main objectives of its implementation can improve the efficiency and effectiveness of the company, especially for the smooth running of business processes. The results of trials and evaluations conducted on E-Commerce web applications can increase product sales and increase business competition.
\end{abstract}

Keywords - Web, E-commerce, OOAD, Implementasi, MySq1

Abstract - Implementasi Web Elektronik ( E-Commerce) yang dapat mempermudah melakukan transaksi pembelian bagi masyarakat dan meningkatkan perdagangan. Implementasi Web Elektronik ( E-Commerce) menggunakan metode OOAD(Object Oriented Analisis Design). Tahapan pengembangan Pemodelan desain menggunakan analisis permasalahan, dan kebutuhan aplikasi pemasaran, desain model proses, desain model data, pembuatan program aplikasi, implementasi aplikasi. Penelitian ini berfungsi untuk mengetahui Penggunaan internet di masa kini sudah mengalami perkembangan dan pemberian manfaat yang signifikan pada bidang bisnis. Hal ini terutama dirasakan oleh perusahaan skala besar. Sasaran utama implementasinya mampu meningkatkan efisiensi dan efektivitas perusahaan terutama bagi kelancaran proses bisnis. Hasil uji coba dan evaluasi yang dilakukan pada aplikasi web E-Commerce ini mampu meningkatkan penjualan produk dan meningkatkat persaingan bisnis perusahaan

Kata kunci - Web, E-commerce, OOAD, Implementasi, MySql

\section{PENDAHULUAN}

Pada saat ini teknologi informasi mengalami perkembangan yang sangat cepat, seiring dengan kebutuhan manusia yang juga terus bertambah. Teknologi yang tidak biasa mengikuti perkembangan teknologi, maka dapat dipastikan akan menjadi orang terbelakang E-commerce merupakan cara bagi konsumen untuk dapat membeli barang yang diinginkan dengan memanfaatkan teknologi internet[1].

Manfaat yang diperoleh dengan menggunakan transaksi melalui e-commerce adalah untuk meningkatkan pendapatan dengan menggunakan penjualan online yang biayanya lebih murah dan juga sekaligus biaya-biaya operasional seperti kertas, pencetakan katalog atau struk bukti pembayaran[3]. Ecommerce merupakan bagian dari e-business, di mana cakupan e-business lebih luas, tidak hanya sekadar perniagaan tetapi mencakup juga pengkolaborasian mitra bisnis, pelayanan nasabah, lowongan pekerjaan dll. Selain teknologi jaringan www, e-commerce juga memerlukan teknologi basisdata atau pangkalan data (databases), surat elektronik (e-mail), dan bentuk teknologi non komputer yang lain seperti halnya sistem pengiriman barang, dan alat pembayaran untuk e-dagang ini.

Masalah dalam mengimplementasikan web ecommerce ini banyak sekali kendala yang dialami yaitu mulai dari perancangan web site, interaksi antara pembeli dengan web site, sering terjadi kesalahan dalam transaksi keuangan, keterlamabatan dalam penghitungan stok barang, gaji karyawan. Tujuan dengan adanya implementasi Web Elektronik E-Commerce dapat meningkatkan persaingan bisnis perdagangan, dapat menjual produk lebih banyak, 
dapat mengurangi infrastruktur perusahaan, Pengurangan Biaya Perusahaan/ Meningkatkan Keuntungan Bersih, Pengurangan Harga Produk. Manfaat dengan penjualan online ini dapat Belanja 24/7, Menghemat Waktu, Barang/Jasa Semakin Murah, Konsumen Mampu Membandingkan Lebih Akurat, Pembeli lintas Wilayah.

\section{METODE PENELITIAN}

Model Pengembangan Perangkat Lunak mengunakan konsep OOAD adalah metode pengembangan sistem yang lebih menekankan pada objek dibandingkan dengan data atau proses. Dalam Tahapan nya OOAD terbagi menjadi dua yaitu OOA (Object oriented analysis) Dan OOD (Object Oriented Design).

Adapun langkah-langkah dalam OOA adalah sebagai berikut :

\section{Menganalisis masalah}

Data-data yang diperlukan untuk pembangunan suatu sistem dikumpulkan sebagai kebutuhan sistem. Setelah semua data-data terkumpul, penulis melakukan analisa untuk merumuskan permasalahan yang terjadi. Kemudian penulis menganalisa dan menggambarkan aliran sistem yang lama dari data yang telah didapat sebelumnya.

2. Menjelaskan proses yang terjadi dalam sistem

Fungsi dari sistem yang akan dibangun bersumber dari data-data yang diperlukan untuk pembangunan suatu sistem dikumpulkan digambarkan. Pada penelitian ini semua data-data yang diperlukan untuk membuat sistem digambarkan dalam bentuk rancangan analisis. Adapun rancangan analisis yang digunakan pada penelitian ini adalah usecase diagram, class diagram, sequence diagram.

3. Identifikasi Objek

Objek adalah benda yang secara fisik dan konseptual yang ada disekitar kita.

4. Menentukan atribut

Atribut disebut juga dengan class yaitu definisi umum dari himpunan objek yang sejenis. Kelas menetapkan spesifikasi perilaku (behaviour) dan atribut-atribut dari objek tersebut. Class adalah abstraksi dari entitas dunia nyata.

\section{Mendefinisikan Operasi}

Maksudnya yaitu menjelaskan operasi yang memungkinkan bisa untuk di implementasikan dan yang tidak bisa di implementasikan.

\section{A. $\quad O O D$ (Object Oriented Design)}

Adapun tahan dari Object Oriented Design (OOD) yaitu :

1. Desain Subsistem

Berisikan representasi masing-masing subsistem yang memungkinkan perangkat lunak mencapai persyaratan yang didefinisikan oleh pelanggannya dan untuk mengimplementasikan infrastruktur yang mendukung persyaratan pelanggan. Desain subsistem ini menggambarkan tabel-tabel yang digunakan dalam sistem.

2. Desain Objek dan Kelas

Berisi hirarki kelas yang memungkinkan sistem diciptakan dengan menggunakan generalisasi dan spesialisasi yang ditarget secara perlahan. Lapisan ini juga berisi infrastruktur yang mendukung persyaratan pelanggan. Desain objek dan kelas ini meliputi gambaran relasi dari tiaptiap kelas/objek yang ada pada sistem.

3. Desain Pesan

Berisi detail yang memungkinkan masingmasing objek berkomunikasi dengan kolaboratornya. Lapisan ini membangun interface internal dan eksternal bagi sistem tersebut.

\section{B. Metode Pengembangan Perangkat Lunak}

Metode yang di gunakan penulis untuk pengembangan perangkat lunak dalam penelitian ini yaitu metode berorientasi objek yang memiliki konsep kelas, objek, metode atribut, enkapsulasi pewarisan antar muka, reusability, generalisasi, spesialisasi, dan komunikasi antar objek, polimorfisme, dan package.[2].

\section{Tools/alat bantu Pengembangan Sistem}

Dalam penelitian ini penulis menggunakan tools UML (unified modeling language), di mana terdapat 13 macam diagram di dalamnya, namun dari 13 macam diagram tersebut penulis hanya menguakan 6 diagram, yaitu :

\section{Activity Diagram}

Activity diagram lebih pokus kepada menggambarkan proses bisnis dan urutan aktivitas. Dan di pakai pada bussines modeling untuk memperlihatkan urutan aktivitas proses bisnis dan activity di buat berdasarkan sebuah atau beberapa use case pada use case diagram. Dan memiliki manfaat lain yang apabila kita membuat diagram ini terlebih dahulu dalam memodelkan sebuah proses untuk membantu memahami subuah proses secara keseluruhan. 


\section{Use Case Diagram}

Use case diagram menggambarkan kebutuhan sistem yang di butuhkan dengan nyata siapa saja yang akan menggunakan sistem dan dengan cara apa pemakai dapat saling berhubungan dengan sistem. Dengan kata lain, use case diagram menggambarkan hubungan antara actor dan use case.

\section{Class Diagram}

Membantu dalam visualisasi struktur kelas dari suatu sistem dan hubungan antar kelas dari penjelasan detail tiap kelas.

\section{Deployment Diagram}

Deployment diagram merupakan gambaran proses-proses berbeda pada suatu sistem yang berjalan dan bagaimana realissasi di dalamnya. Hal inilah yang mempermudah user dalam pemakaian sistem yang telah di buat dan diagram bersipat statis. Misalnya untuk mendeskripsikan sebuah situs web, deployment diagram menunjukan komponen perangkat lunak apa yang berjalan pada setiap note dan bagaimana bagian bagian yang berbeda terhubung.

\section{Sequence diagram}

Suatu diagram yang menggambarkan skanario atau rangkaian langkah-langkah yang di lakukan sebagai sebuah respon dari kejadian/even untuk menghasilkan suatu output tertentu. Diagram ini secara khusus bersosialisasi dengan usecase diagram, memperlihatkan tahap demi tahap apa yang seharusnya terjadi untuk menghasilkan sesuai di dalam usecase.

\section{Website}

Website adalah sekumpulan halaman web yang di letakkan dalam suatu tempat/situs. Jadi website terdapat halaman-halaman web beserta halaman pendukungnya, seperti gamabar, video, audio, dan file digital lainnya yang di letakkan dan suatu tempat yang di identifikasikan melalui nama domain (domain name) dan alamat IP (Ip Addres) dan halaman web inilah yang di tulis menggunakan standar bahasa HTML[4]

\section{E. $M y S Q L$}

MySQL merupakan sebuah perangkat lunak atau software sistem manajemen basis data SQL atau DBMS Multithread dan multi user. MySQ1 sebenarnya merupakan turunan dari salah satu konsep utama dalam database untuk pemilihan atau seleksi dan pemasukan data yang memungkinkan pengoperasian data dikerjakan secara mudah dan otomatis[5].

\section{F. $X A M P P$}

$X A M P P$ adalah perangkat lunak bebas, yang mendukung banyak sistem operasi, merupakan kompilasi dari beberapa program. Fungsinya adalah sebagai server yang berdiri sendiri (localhost), yang terdiri atas program Apache HTTP Server, MySQL database, dan penerjemah bahasa yang ditulis dengan bahasa pemrograman PHP dan Pell. Nama XAMPP merupakan singkatan dari $X$ (empat sistem operasi apapun), Apache, MySQL, PHP dan Perl. Program ini tersedia dalam GNU General Public License dan bebas, merupakan web server yang mudah digunakan yang dapat melayani tampilan halaman web yang dinamis

\section{G. Adobe Dreamweaver}

Adobe Dreamweaver merupakan program penyunting halaman web keluaran Adobe Systems yang dulu dikenal sebagai Macromedia Dreamweaver keluaran Macromedia. Program ini banyak digunakan oleh pengembang web karena fitur-fiturnya yang menarik dan kemudahan penggunaannya. Versi terakhir Macromedia Dreamweaver sebelum Macromedia dibeli oleh Adobe Systems yaitu versi 8. Versi terakhir Dreamweaver keluaran Adobe Systems adalah versi 12 yang ada dalam Adobe Creative Cloud (sering disingkat Adobe Cc)[5].

\section{H. Adobe Photoshop}

Adobe Photoshop, atau biasa disebut Photoshop, adalah perangkat lunak editor citra buatan Adobe Systems yang dikhususkan untuk pengeditan foto/gambar dan pembuatan efek, serta bias di gunakan untuk membantu merancang pembuatan sebuah web menjadi lebih menarik[6]. Perangkat lunak ini banyak digunakan oleh fotografer digital dan perusahaan iklan.

\section{HASIL DAN PEMBAHASAN}

\section{A. Analisa data Proses Bisnis}

kustomer langsung datang ke toko lalu memilih produk yang di inginkannya. Lalu kustomer menunjukkan produk yang di pilih ke bagian penjualan, lalu bagian penjualan menerima produk dan menyerahkan produk kebagian kasir, kasir menerima produk lalu kasir mengecek harga produk dan melakukan konfirmasi harga total pembayaran, pelanggan bayar total pembayaran dan kustomer serah total pembayaran lalu kasir terima total pembayaran ,kasir serah produk dan kustomer terima produk tersebut. 


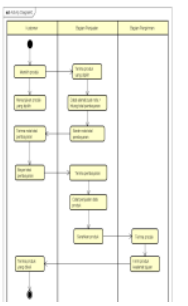

Gambar 1. Activity Diagram Order Produk

\section{B. Use Case Diagram}

Dalam Proses perdagangan E- Elektronik atau ECommerce dapat menggambarkan kebutuhan sistem dari sudut pandang pengguna dalam melakukan aktivitas proses sistem informasi perdagangan eelektronik atau e-commerce maka dapat gambarkan dengan usecase diagram dengan gambar dibawah ini :

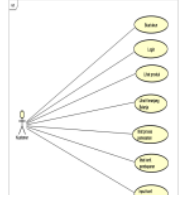

Gambar 2. Use Case Diagram Berdasarkan Admin

\section{Perancangan Data Base}

Data bese yang di rancang menggunakan beberapa tabel yaitu Konsumen, Produk, Katagori produk, kirim, order, order history, jasa kirim, kota, mod bank yang digambarkan kedalam sebuah diagram LRS( Logikal Recors Structure )

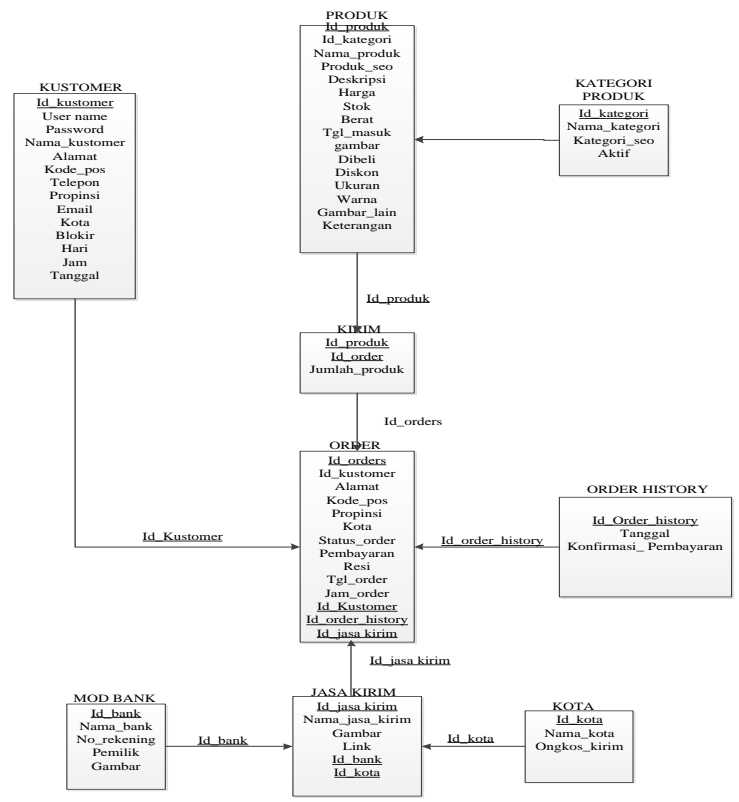

Gambar 3.Logical Record Strucutural (LRS) 


\section{Hasil Implementasi}

1. Menu Struktur Tampilan

Struktur tampilan pada sistem informasi penjualan online - e-commerce pada toko pecah belah center pangkalpinang yang terdiri dari Menu Admin, menu konsumen dan menu keluar dari sistem. Menu admin terdiri dari aktivitas buat akun, login, lihat produk, lihat kerenjang belanja, lihat proses pemesanan, input konfirmasi pembayaran, lihat konfirmasi pembayaran. Proses menu konsumen yaitu login, input kategori produk, input ongkir, lihat data konsumen, input rekening pembayaran, input jasa pengiriman, lihat order masuk, lihat testimoni, input dan cetak laporan penjualan.

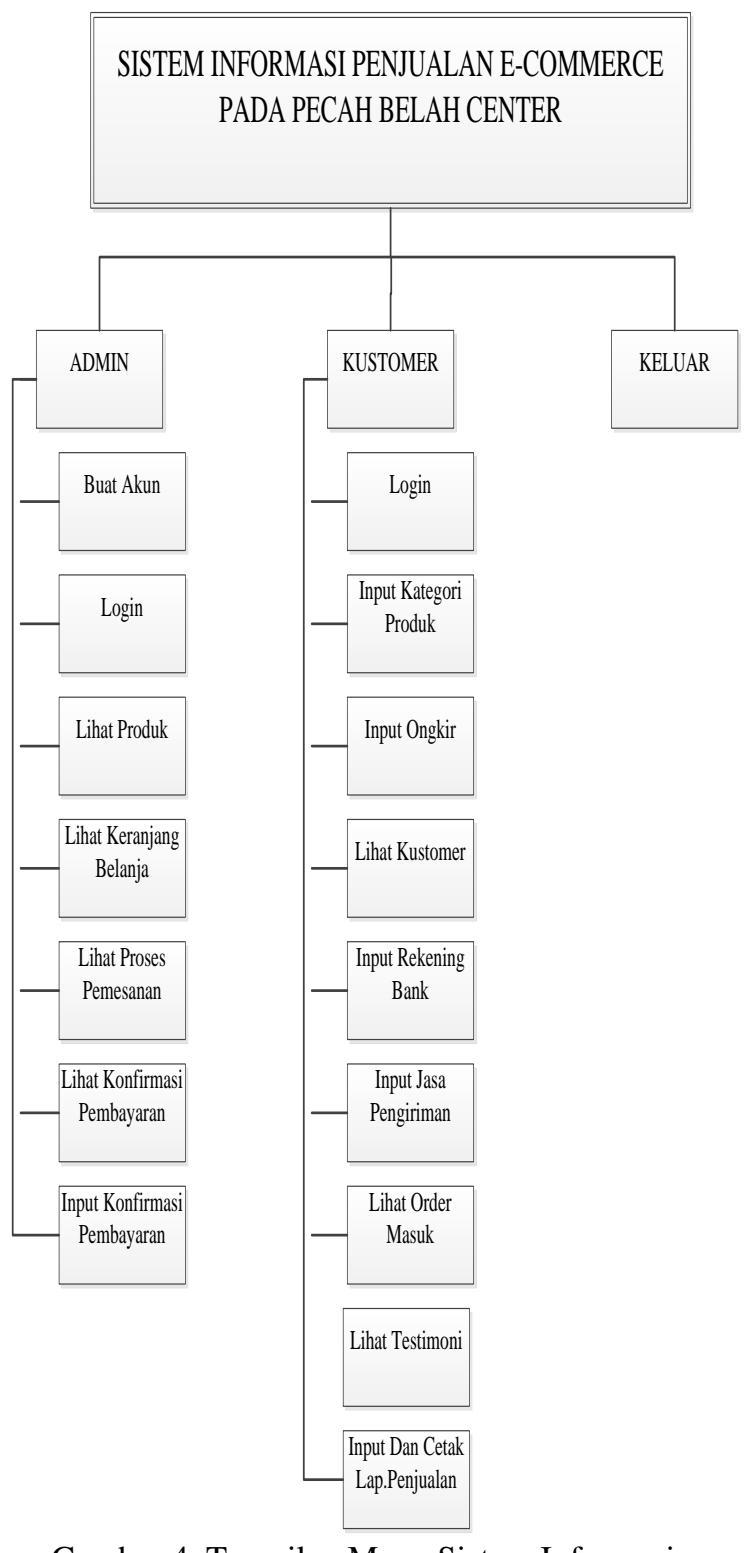

Gambar 4. Tampilan Menu Sistem Informasi Penjualan Online E-Commerce Pada Toko Pecah Belah

\section{Tampilan Login Admin}

Tampilan menu ini digunakan untuk login administrator sebelum memproses website. Jika tidak login maka tidak bisa mengakses web site

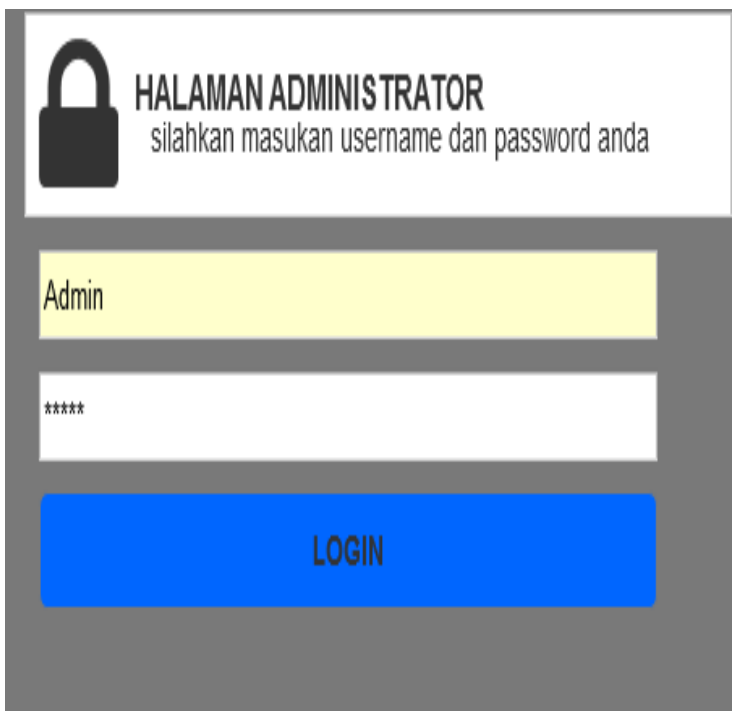

Gambar 5. Tampilan Menu Login

3. Halaman menu Utama

Halaman ini adalah halaman yang digunakan untuk pengunjung melihat toko pecah belah center.

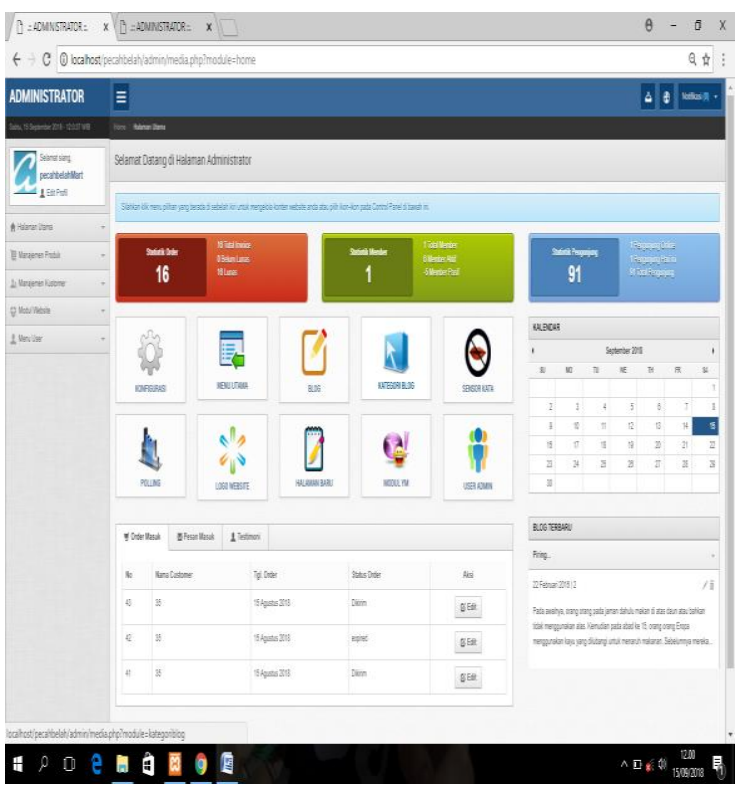

Gambar 6. Tampilan Menu Utama

4. Halaman Tampilan Katagori Produk

Tampilan digunakan untuk memilih produk yang ingin di pesan yang dilakukan oleh konsumen. 


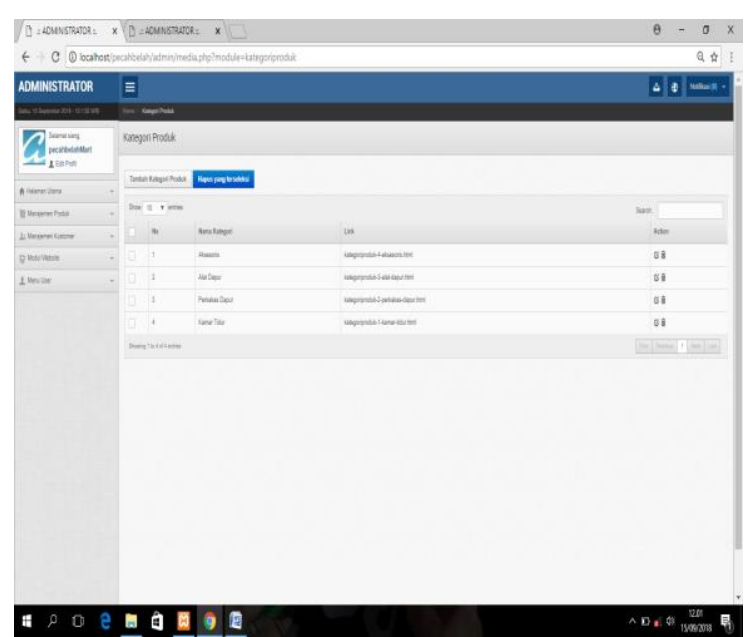

Gambar 7. Tampilan Menu Kategori Produk

5. Halaman tampilan keranjang Produk

Halaman tampilan yang digunakan untuk meng konfirmasikan pesanan kedalan keranjang produk.

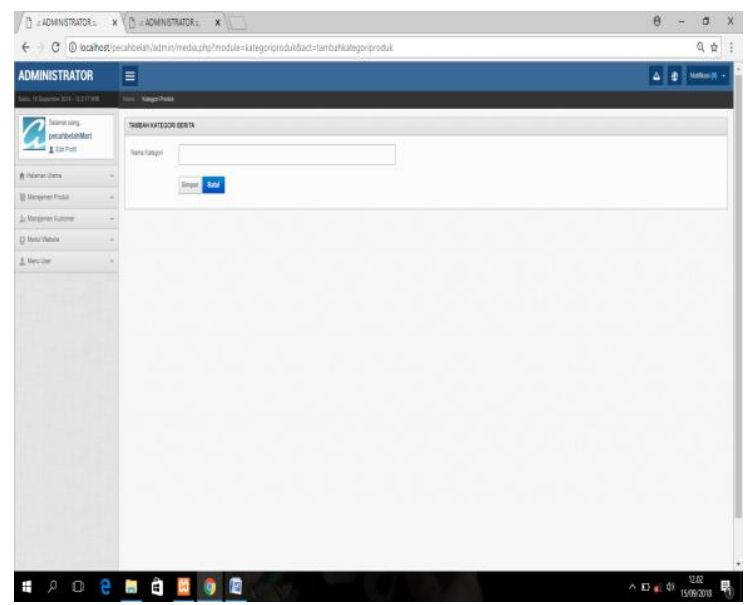

Gambar 8. Tampilan Menu Keranjang Produk

6. Halaman tampilan Order Pemesanan

Halaman tampilan dibawah ini digunakan untuk melakukan order pemesanan yang dilakukan oleh konsumen pada saat melakukan order pesanan

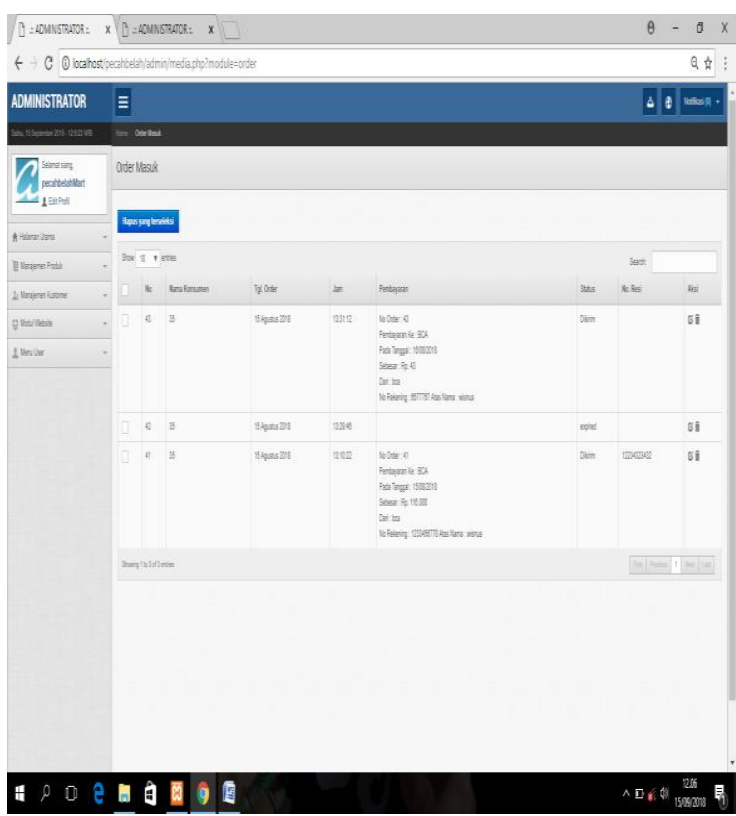

Gambar 9. Tampilan Menu Order Pemesanan

7. Halaman tampilan Pembayaran

Tampilan digunakan untuk melakukan pemilihan jenis pembayaran melalui bank yang dilakukan oleh konsumen pada saaat mau bayar barang yang akan dibeli dan di bayar.

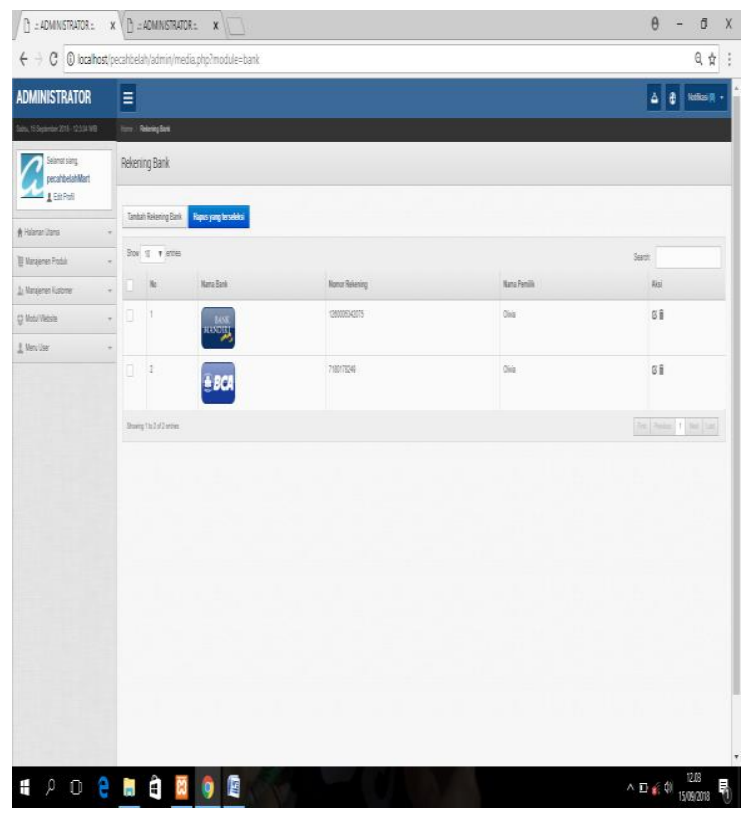

Gambar 10. Tampilan Menu Pembayaran 


\section{Halaman Pembayaran melalui proses rekening}

Halaman ini digunakan untuk mengetahui nomor rekening dari pihak toko yang dilakukan pembayaran oleh konsumen melalui rekening yang sudah ditentukan.

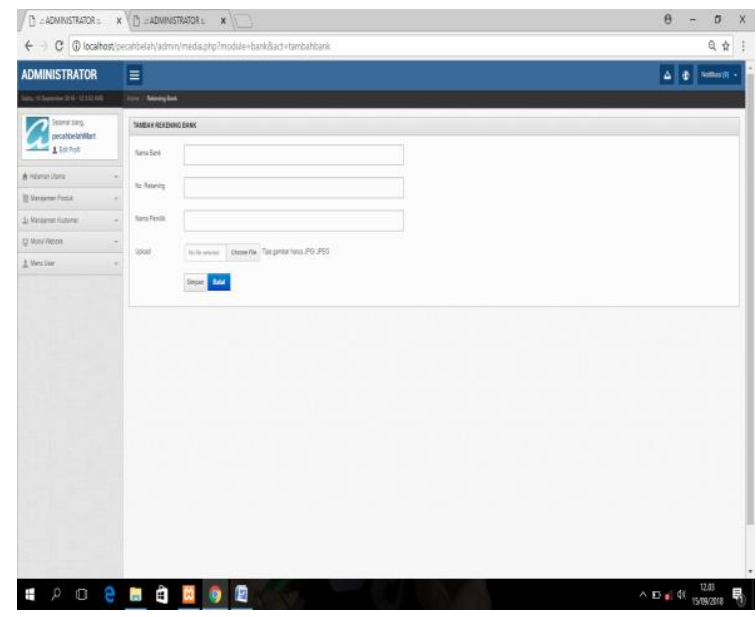

Gambar 11. Tampilan Menu Pemilihan Pembayaran

\section{Halaman tampilan jasa ongkos kirim}

Halaman tampilan dibawah ini digunakan untuk mengetahui berapa pembayaran jasa ongkos kirim yang akan dikirim ke konsumen sesuai dengan daerah masing-masing konsumen.

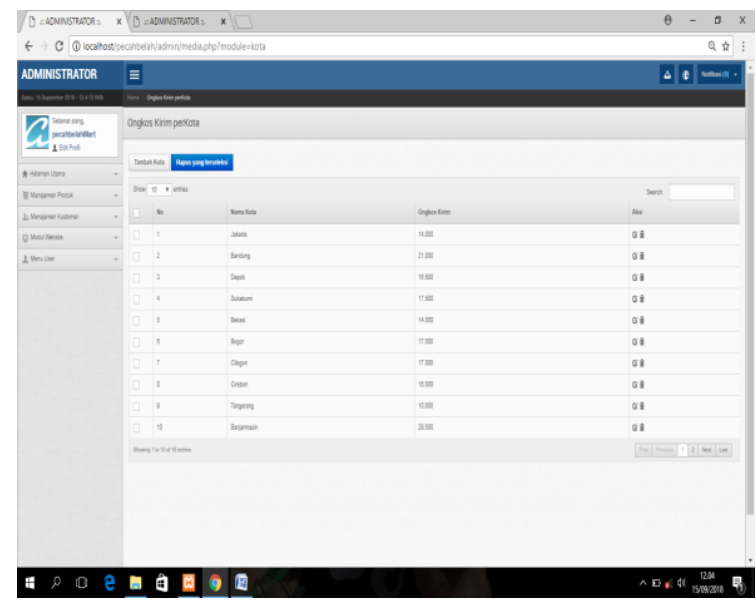

Gambar 12. Tampilan Menu Ongkos kirim

\section{KESIMPULAN}

Dengan cara membuat sistem penjualan online yang dapat lebih efisien di bandingkan dengan yang konvensional. Karena dalam mengakses pemesanan atau pembelian akan lebih mudah. Dan meningkatkan pelayanan dan penjualan di berbagai wilayah baik dalam kota atau pun luar kota, Mempromosikan barang yang di jual dapat di kenal masyarakat luas.
Dengan adanya e-commerce ini aplikasi e-commerce ini di hosting ke internet sehingga selain masyarakat di propinsi Bangka belitung dan masyarakat di luar wilayah dapat mengenal adanya aplikasi penjualan alat rumah tangga, Website ini bisa membantu pihak perusahaan dalam memperluas wilayah pemasaran di wilayah Bangka Belitung.

Dalam pembuatan website e-commerce ini, penulis berharap agar bermanfaat bagi pihak perusahaan dan bisa menambah kualitas pelayanan yang diberikan. Dengan adanya website ini perkembangan teknologi informasi dan komunikasi semakin berkembang luas dalam membantu sarana perdagangan. Adapun saransaran yang ingin penulis berikan untuk kemajuan dalam sistem ini adalah :

a. Tersedianya sumber daya manusia dalam mengjalankan website ini agar berjalan dengan baik.

b. Dapat diharapkan agar kedepannya untuk lebih meningkatkan keamanan website ini.

c. Untuk perkembangan sistem selanjutnya agar pihak yang menggunakan website ini baik perusahaan ataupun pribadi di beri pendidikan mengenai pelayanan e-commerce berbasis website,sebagaimana cara menggunakan website tersebut, serta kerjasama dan kekompakan tim agar tercipta koordinasi yang baik.

d. Untuk menjadikan perkembangan yang diharapkan dapat menambahkan pengamanan dan upload bukti pembayaran dalam konfirmasi pembayaran sehngga dapat mengurangi potensi kecurangan yang terjadi disaat pelanggan melakukan konfirmasi pembayaran.

e. Untuk mengatasi kerusakan sistem maupun perangkat keras, maka sebaiknya dalam jangka waktu tertentu di lakukan back up data dari database yang di buat ke dalam penyimpanan luar baik hard diskdan lain sebagainya.

\section{DAFTAR PUSTAKA}

[1] Haryanti, Sri. Tri Irianto, "Rancang Bangun Sistem Informasi E-Commerce Untuk Usaha Fashion Studi Kasus Omah Mode Kudus," Jurnal Speed-Sentra Penelitian Engineering dan Edukasi, vol. Vol. 3, no. 1, pp. 8-14, 2011

[2] A.S, Rosa dan M. Shalahuddin, 2015, Rekayasa Perangkat Lunak Terstruktur dan Berorientasi Objek, Informatika, Bandung

[3] Kadir, Abdul, 2014, Membuat Desain Ecommerce, Andi, Yogyakarta

[4] Pratama, I putu agus eka, 2015, E-Commerce, EBussines and Mobile Commerce Berbasis open source, Informatika, Bandung

[5] Hakim Lakmanul, Rahasia Inti Master PHP dan MYSQL (improved), Lekomedia, 2014, Yogyakarta

[6] Subagia Anton, Pakar Fhotoshop Desain dan Grafik, Dapur Buku, 2013, Jakarta 
[7] Hakim Lakmanul, Rahasia Inti Master PHP dan MYSQL (improved), Lekomedia, 2014, Yogyakarta

[8] Subagia Anton, Pakar Fhotoshop Desain dan Grafik, Dapur Buku, 3013, Jakarta

[9] Jarot S, Darma dan Shenia Ananda, 2009, Buku Pintar Menguasai Internet,Ed.I, Mediakita,Jakarta Selatan 